\title{
A Dual-Band MIMO Monopole Antenna System for Set Top Box and WLAN Chipsets
}

\author{
Adnan Kaya*1, Cem Baytöre ${ }^{1}$, Merih Palandöken ${ }^{1}$, Irfan Kaya², Basak Ozbakis ${ }^{2}$ \\ ${ }^{1}$ Izmir Katip Celebi University \\ Cigli, Izmir, Turkey \\ *adnan.kaya@ikc.edu.tr \\ ${ }^{2}$ Anadolu University, Department of Vestel R\&D Project \\ Eskişehir, Manisa, Turkey
}

\begin{abstract}
In this paper, a compact monopole microstrip antenna is presented for dual-band WLAN mobile modules operating in 2.4 $\mathrm{GHz}$ and $5.2 \mathrm{GHz}$ bands. A novel dual-broadband multiple-input-multiple- output (MIMO) antenna Set Top Box (STB) system is developed. The bandwidths (return loss $10 \mathrm{~dB}$ ) achieved for the dual-band antenna element are $2.4 \mathrm{GHz}(20 \%)$ for the lower band and $5.2 \mathrm{GHz}(38 \%)$ for the upper band. Various configurations of this monopole antenna for MIMO application are also studied. It is shown that good MIMO performance can be achieved even for small element spacing. Simulation results are compared and discussed. Promising small-size WLAN monopole antenna suitable to be mounted along the front edge of the STB with metal housing is presented. The antenna is formed by a two branch structure of a monopole strip and a loop strip. The antenna has attractive features of low profile and wideband operation.
\end{abstract}

Keywords: WLAN compact antenna, MIMO, L-shaped strip resonator, Set Top Box

\section{Introduction}

In recent years, wireless communication systems have increased rapidly. In high-bit-rate wireless communication for reduced multipath fading and increased capacity, multiple-input-multiple-output (MIMO) systems are suitable. The MIMO antenna array should have compact structure, high radiation efficiency, low envelope correlation, and high isolation between the signal ports [1]. To achieve maximum channel capacity the array is also required having high gain and wide lobe pattern [2].

Various works on planar (MIMO) technologies play an essential role in the emerging or the future wireless communications, such as Long Term Evolution (LTE) and WiMAX, STB systems [1] or wireless local area networks (WLANs) [2]. The next generation of wireless communication networks integrates existing systems such as GSM/UMTS/WLAN into the future LTE/4G systems to create a heterogeneous system with improved capacity and complementary coverage [3]. Therefore, a broadband multifrequency MIMO antenna system is essential for multifunctional GSM/UMTS/LTE and WLAN communication handsets. Over the past 10 years, a large number of MIMO/diversity antenna systems has been investigated for mobile/wireless handsets [4]-[7]. Most of the MIMO/diversity antennas were developed for WLAN/WiMAX/LTE handsets in a single band, such as the 2.4-GHz band [4], the 5-GHz band [5], the 3.5-GHz band [6], or the 2.6-GHz band [7]. Dual-band MIMO antennas were also developed for the 2.4/5-GHz WLAN bands [8], the GSM 900-MHz/WLAN 2.4-GHz bands [9], or the UMTS (1920-2170 MHz)/WLAN 2.4-GHz bands [10].

On the other hand, the dual-band operability of the compact antennas within the allocated bandwidths has become a common sense for high speed data transmission enabling multifunctional services in one electronic device. The continual customer demands in wireless services for diverse WLAN applications have initiated different antenna structures to be designed with low-profile, light weight, flush mounted to fit the limited physical space of commercial portable components. The MIMO antenna system covers two band frequency ranges: 2-2.7 and 5.2-5.8 GHz. A dual-band antenna element is first proposed, and then a two-element MIMO antenna system is developed.

The paper is organized in the following manner. In Section II, the design principle of the proposed WLAN MIMO antenna is explained with the geometric parameters. In Section III, the numerical calculations of the reflection parameter is 
illustrated with the pattern performances at the resonance frequencies to explain the antenna operation principle. The radiation patterns at the lower and higher frequency bands are also shown for closed set top box (STB).

\section{Proposed WLAN MIMO Antenna}

The proposed compact dual-band monopole antennas are shown in Figure 1. The proposed L-shaped monopole antenna can create a single resonance within the 802.11/n range. Placement of two slots within the monopole antenna creates two extra resonances whose center frequencies can be adjusted by the L-shaped monopole and the slots parameters. The antenna parameters for WLAN application, covering 2.4, 5.4, and $5.8 \mathrm{GHz}$, are given. The MIMO antenna consists of two dual-broadband antenna elements, each of which comprises two opened loops: an outer loop and an inner loop. The opened outer loop acts as a half-wave dipole and is excited by electromagnetic coupling from the inner loop, leading to a broadband performance for the lower band. A combination of the two monopoles and the higher modes from the outer loop results in a broadband performance for the upper band.

In addition, by using the closed resonant path provided by the loop strip, possible coupling of the proposed antenna with nearby conducting elements for frequencies over the $2.4 \mathrm{GHz}$ band can be expected to be decreased. Also, when the antenna is operated in the 5.2/5.8 GHz band, the loop strip is not at resonance and can serve as a shielding element for the monopole strip. This can also lead to decreased possible coupling of the proposed antenna with nearby conducting elements over the 5.2/5.8 GHz band. Figure 1 shows the geometries of the proposed dual-band antenna. The antenna is fabricated on a FR4 substrate with a thickness of $1.6 \mathrm{~mm}, 0.8 \mathrm{~mm}$ and a relative permittivity of 4.4 . This antenna is fed on the L-shape monopole by a $50 \mathrm{ohm}$ coaxial cable.

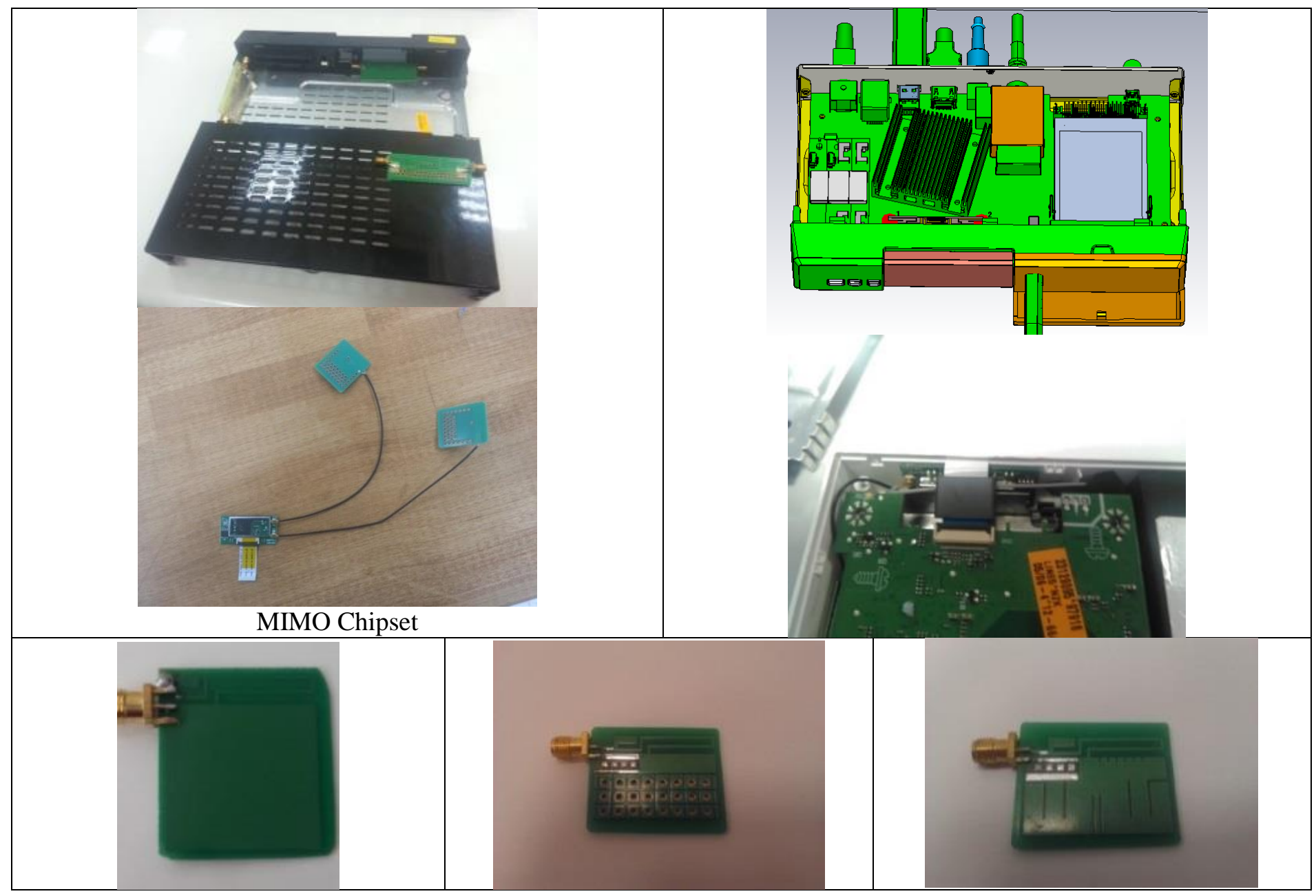

Fig. 1: STB antenna geometries (STB with metal housing in the closed state _Avastar 88W8897 serial 2*2 MIMO chip). 
The proposed WLAN monopole antenna is basically composed of two microstrip line resonators on the top of $1.52 \mathrm{~mm}$ thick FR4 substrate with the material parameters of relative permittivity 4.4 and loss tangent 0.02 . These resonators are directly connected to the feeding line in the form of an asymmetric coplanar transmission line to have more efficient field coupling through the galvanic connection. The proposed antenna has the overall size of $0.08 \lambda_{0} \times 0.16 \lambda_{0}$ at the lower resonance frequency.

The physical parameters of L-shaped resonator are determined to have $\lambda_{0} / 4$ resonance at the higher frequency band. The resonance current distribution at the lower frequency band is due to $\lambda_{0} / 2$ resonance excitation of the combination of ring and spiral resonators. In other words, the electrical length of the ring resonator is increased with the additional spiral resonator. The important point in the design is to determine at which part of the resonator has to be directly connected to the feeding line. The ground plane size and feeding line length are optimized for best return loss in two frequency bands due to the impedance transformation feature of feeding line and ground plane.

\section{Monopole Antenna Simulation and Measurement Results}

The return loss of the compact WLAN antenna is numerically calculated with commercial 3D FIT based electromagnetic field simulator CST. The reflection parameter is shown in Figure 2.

The proposed antenna versions were simulated and measured in Fig. 2. The simulated return loss of the proposed antennas are shown in Fig. 2. The simulated result shows that the $10 \mathrm{~dB}$ return loss is satisfied at each operating band, and has a good agreement with $802.11 / \mathrm{n} / \mathrm{ac}$. The antenna return loss is better than $10 \mathrm{~dB}$ in the lower frequency band between 2.2 $\mathrm{GHz}$ and $2.6 \mathrm{GHz}$ with the maximum value of $16 \mathrm{~dB}$ at $2.41 \mathrm{GHz}$, and in the higher frequency band between $5 \mathrm{GHz}$ and 5.6 $\mathrm{GHz}$ with the maximum value of $19 \mathrm{~dB}$ at $5.14 \mathrm{GHz}$.

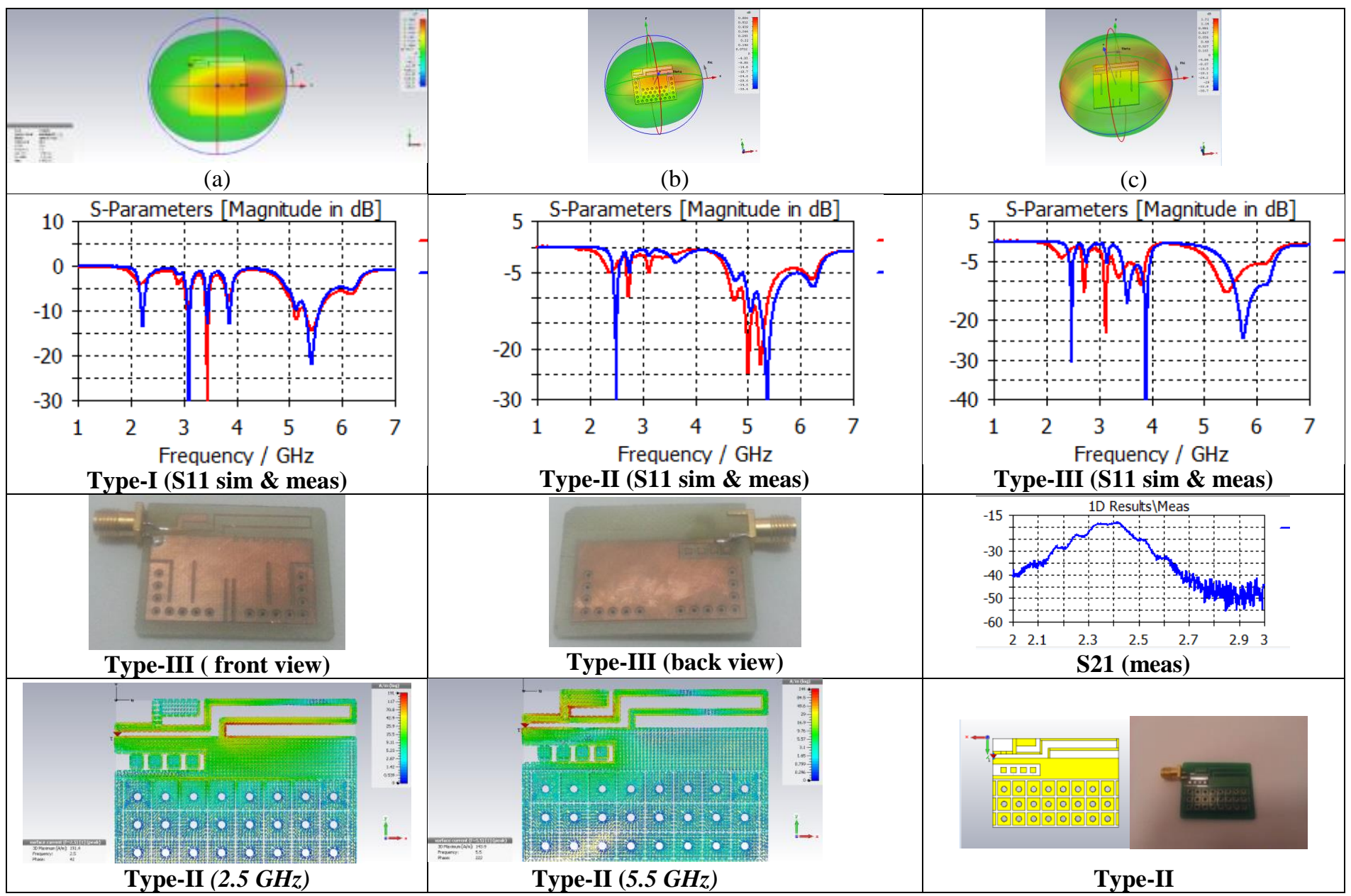

Fig. 2: Simulated S11 and farfield results of dual band antenna elements generation (a) Type I (b) Type II (c) Type III. 
The return loss performances at two resonant frequencies are shown in Figure 2, which indicates the main operation principle of the antenna. Two antennas were placed centrally on each edge of the STB as shown in the drawing in Figure 1. WLAN monopole antenna measurement and simulated farfield results for (Type III) are shown in Fig.3.

\begin{tabular}{|c|c|c|c|}
\hline 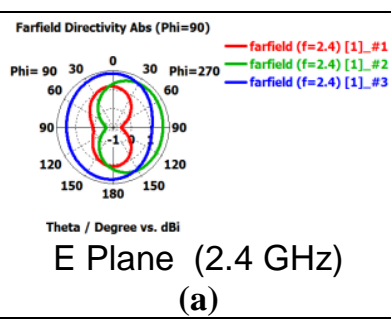 & 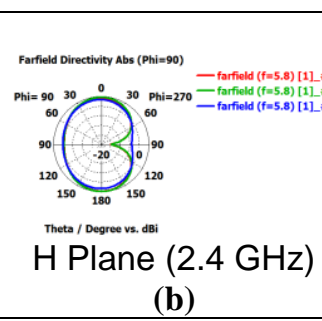 & 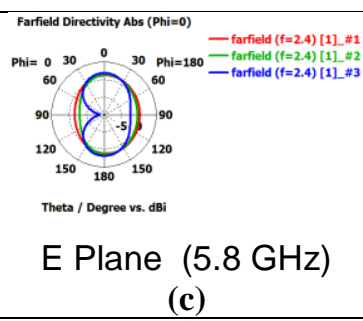 & 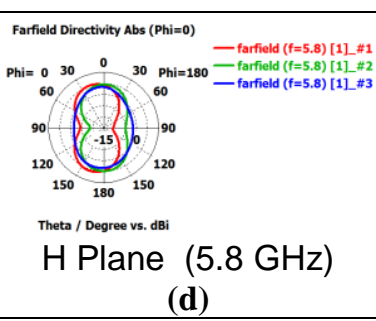 \\
\hline $\begin{array}{l}\text { Origin } \\
\text { (e) }\end{array}$ & $\begin{array}{l}\text { Theta } 0 \text { Phi } 0 \text {, } \\
\text { (f) }\end{array}$ & $\begin{array}{c}\text { Theta } 180 \text { Phi } 0 \\
\text { (g) }\end{array}$ & $\begin{array}{c}\text { Theta } 90 \text { Phi } 0 \\
\text { (h) }\end{array}$ \\
\hline 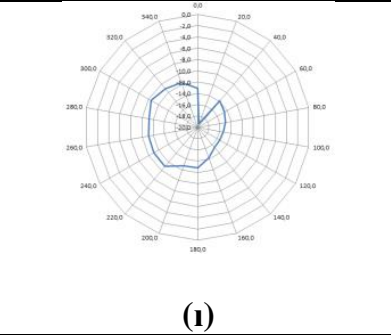 & $(\mathbf{j})$ & (k) & 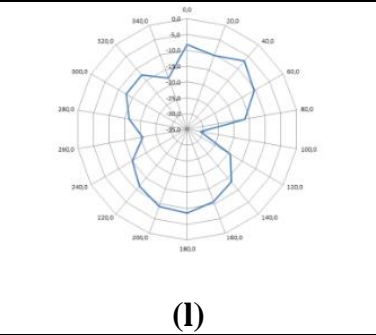 \\
\hline
\end{tabular}

Fig. 3: Measurement and Simulated farfield results for WLAN monopole (Type III).

\section{Monopole Antenna Embedded in the STB with Metal Housing}

The proposed antenna mounted along the front -end of the set top box with metal housing is shown in Fig.4(a). The metal housing is modeled as VESTEL STB metal plates considered as the upper metal cover and base metal cover, both connected through the front position. STB antenna array (a photo of the fabricated prototype is shown in Fig. 4) mounted at the front edge of the supporting PVC plate of the STB display. The dimensions of the supporting metal plate are $230 \times 120$ $\mathrm{mm} 2$. The two antennas have a similar geometry of a driven strip and a shorted strip. The antennas have a wide lower band to cover the $2.4 \mathrm{GHz}$ WLAN operation and a wide upper band to cover the 5.2/5.8 GHz WLAN operation. The $2.4 \mathrm{GHz}$ band is formed by a quarter-wavelength resonant mode generated by the shorted strip. The 5.2/5.8 GHz bands are formed by a quarter-wavelength resonant mode generated by the driven strip and a higher-order resonant mode generated by the shorted strip. In this work, the operation of an antenna array integrated into a STB terminal.

The normalized $3 \mathrm{D}$ radiation patterns are shown in Figure 3 for each of frequencies. The radiation efficiencies are $75 \%$ and $80 \%$ at $2.4 \mathrm{GHz}$ and $5.2 \mathrm{GHz}$, respectively.

Two U-shaped slots are introduced to reduce the RL between the Type I and Type II antenna elements. The RL achieved is higher than $15 \mathrm{~dB}$ in the lower band and $20 \mathrm{~dB}$ in the upper band, leading to an envelope correlation coefficient of less than 0.01. The dual-broadband MIMO antenna demonstrates the effect of the STB ground plane on the direction of peak gain. This work by Vestel Ltd. has shown peak gain will follow the path of the longest ground plane as is also demonstrated in this case. It may thus be possible the steer the peak gain to a particular position by moving the element from a central location to one nearer the front edge.

Assuming a propagation scenario where there is an incident field with uniform distribution the envelope correlation can be obtained from the S parameters [2] of the antenna system as 


$$
\left|\rho_{i j}\right|^{2}=\rho_{\mathrm{eij}}=\left|\frac{\left|S *_{i i} S_{i j}+S *_{j i} S_{j j}\right|}{\left|\left(1-\left|S_{i i}\right|^{2}-\left|S_{j i}\right|^{2}\right)\left(1-\left|S_{j j}\right|^{2}-\left|S_{i j}\right|^{2}\right) \eta_{\text {radi }} \eta_{\text {radj }}\right|^{1 / 2}}\right|^{2}
$$

Simulation and Measurements Performance Result are shown in below figure (Fig.4.)

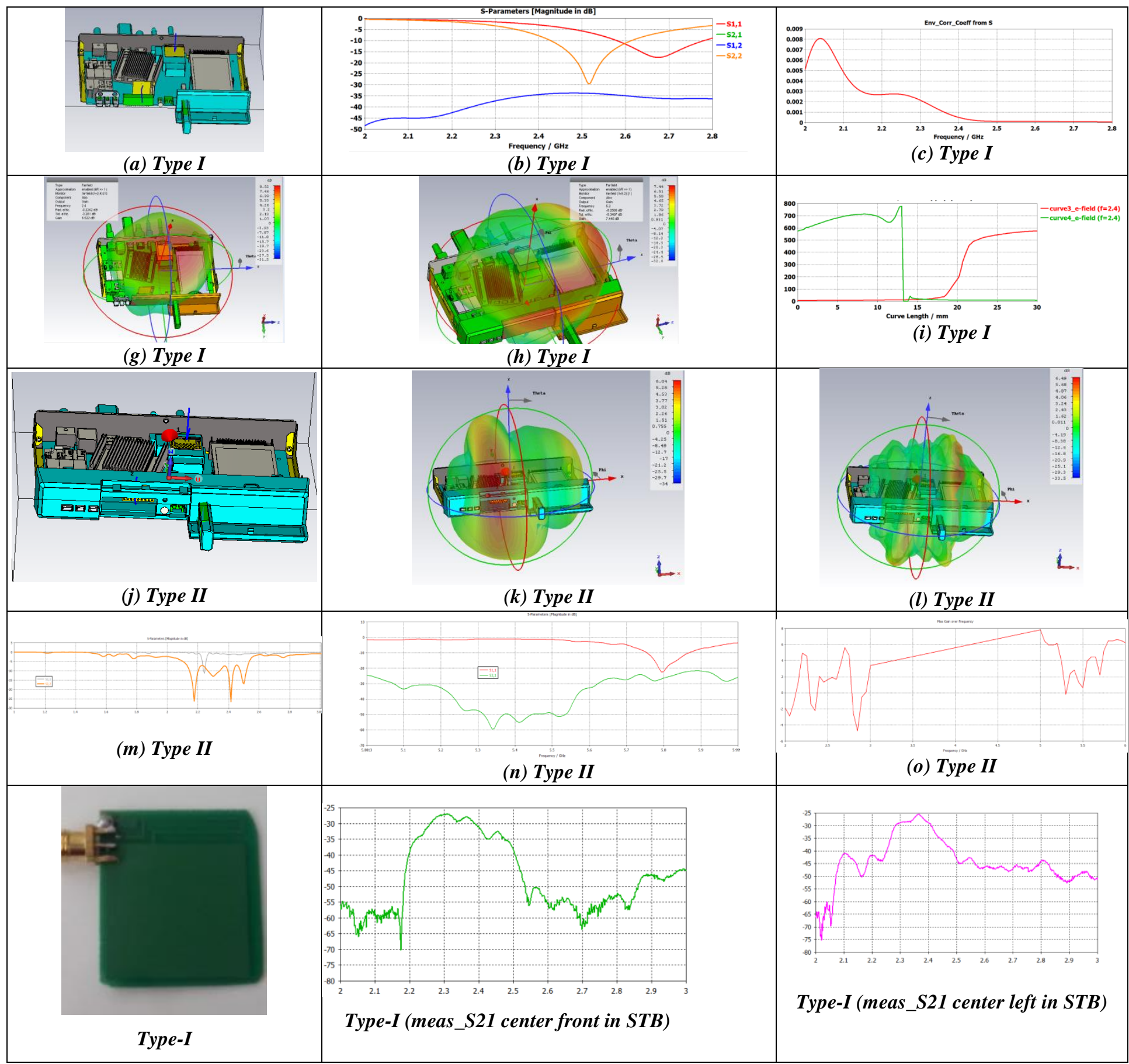

Fig. 4: Sim and Measurements Performance Result. 
Antenna performance results are summarized in table 1. It is clearly seen that Type II produced much better performances.

Table 1: Performance Results in STB.

\begin{tabular}{|c|c|c|c|c|c|}
\hline In STB & Resonance Freq.-Fr & Band Width BW & Max. Gain-G & Efficiency & Corr. \\
\hline Type I & $2 . \mathrm{GHz} \& 2.55 \mathrm{GHz}$ & $30 \mathrm{MHz} \& 200 \mathrm{MHz}$ & $4.83 \mathrm{~dB} \& 5.23 \mathrm{~dB}$ & $-1.35 \mathrm{~dB} \&-0.2 \mathrm{~dB}$ & $0.002 \& 0.002$ \\
\hline Type II & $2.65 \mathrm{GHz} \& 2.5 \mathrm{GHz}$ & $200 \mathrm{~Hz} \& 200 \mathrm{MHz}$ & $8.09 \mathrm{~dB} \& 4.85 \mathrm{~dB}$ & $-1 \mathrm{~dB} \&-0.6 \mathrm{~dB}$ & $\leq 0.001$ \\
\hline Type I & $5.2 \mathrm{GHz} \& 5.1 \mathrm{GHz}$ & $\geq 500 \& \geq 600 \mathrm{MHz}$ & $5.13 \mathrm{~dB} \& \sim 7.5 \mathrm{~dB}$ & $-0.35 \&-0.4 \mathrm{~dB}$ & 0.0002 \\
\hline Type II & $5.2 \mathrm{GHz} \& 5.1 \mathrm{GHz}$ & $\geq 500 \& \geq 600 \mathrm{MHz}$ & $8.13 \mathrm{~dB} \& \sim 9.5 \mathrm{~dB}$ & $-0.35 \&-0.1 \mathrm{~dB}$ & 0.0001 \\
\hline
\end{tabular}
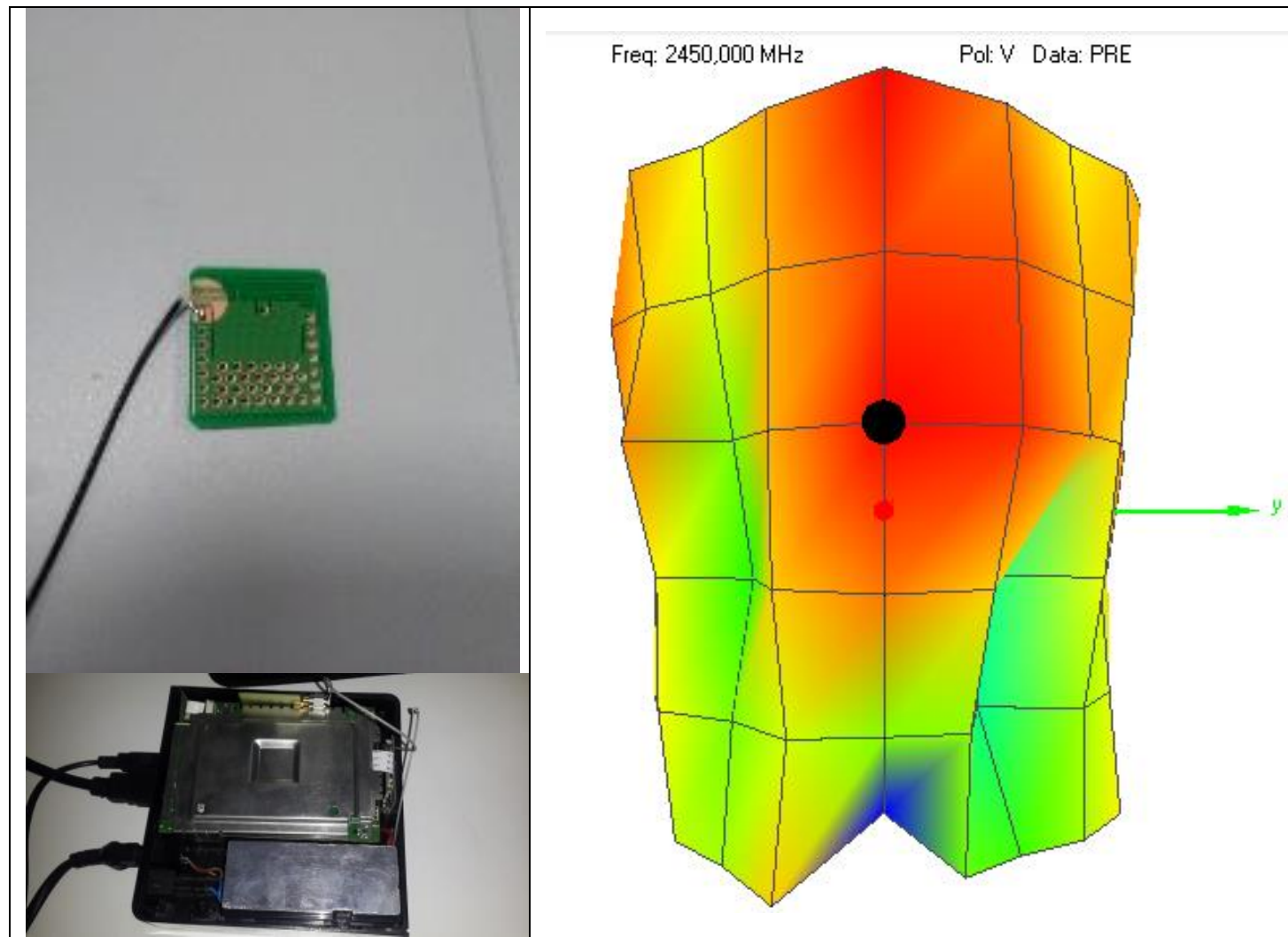

Level: $-9,687 \mathrm{dBuV} / \mathrm{m}$

Phi: $360 \mathrm{deg}$

Height: $160 \mathrm{~cm}$

Data: Raw Data

Node No: 75
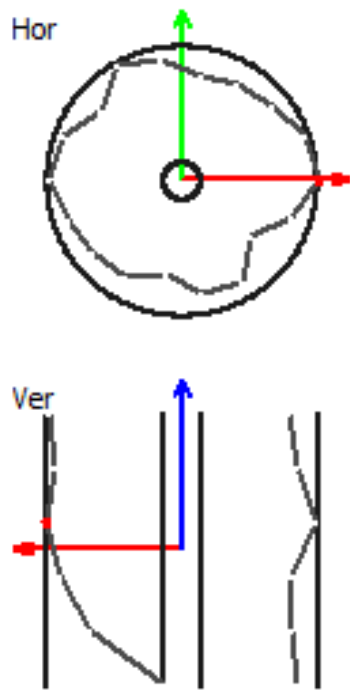

Fig. 5: Antenna Pattern result in STB Type III

A two-element linear array of back-to-back L-shaped patches (Fig. 1) has been introduced in [6]. The radiators are


In the numerical simulations the STB screen has been modelled as a PEC box of dimensions $220 \times 130 \times 40$ [mm $\mathrm{m}^{3}$. An antenna prototype has been built and integrated into a VESTEL chassis (Fig. 1). The good results obtained between numerical simulations has validated the simulation model used [6]. The integrated array has also been measured with the aid of a trueMIMO test bed in the whole range of multipath indoor scenarios [7] and has been shown to be MIMO-capacity preserving. However, the analysis presented in [6] and [7] does not consider the presence of the for actual application, antenna must be integrated with a STB screen. Figures 2 exhibit the simulated far-field radiation patterns on 3D plane for two frequencies at 2.4 and $5.5 \mathrm{GHz}$, respectively. Fig. 2 shows the simulated radiation efficiency and peak gain of the proposed antenna for all bands. The peak gain is about $1: 25 » 6: 38 \mathrm{dBi}$ and radiation efficiency ranges from $67 \%$ to $85 \%$.

As with the symmetrical version, the port-to-port isolation is better than $20 \mathrm{~dB}$ for each combination of antennas. The radiation patterns are also included in table 1 . The radiation patterns for each of the antennas powered individually. 


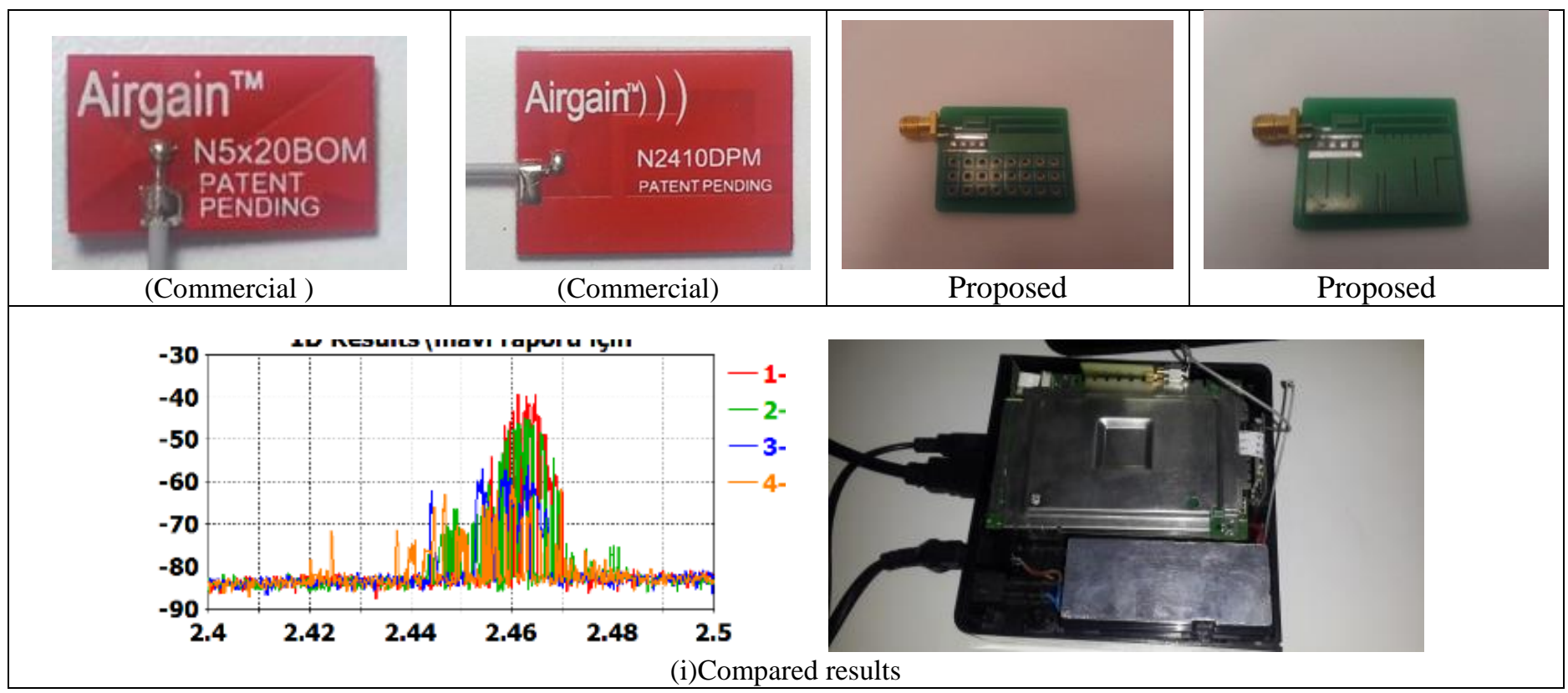

Fig. 6: (a),(b) Airgain N5x20BOMi (b),(g) Airgain N2410DPM, (c) Type II (d) Type III 4 (e) WiFi performance results

The simulations demonstrated the antenna design exceeded the required bandwidth and gave the expected directional gain patterns thus confirming this element as suitable to attempt multiple element integration. A compact printed dual-band antenna for STB applications has been presented in this article. This antenna structure has the advantages of simple structure, small size, easy fabrication, and making integration within STB case. The results are satisfied at each operating band, and demonstrate good results with simulated results.

\section{Conclusion}

A small-size printed WLAN antenna suitable for STB with very thin profile and metal housing has been presented. The antenna has $120 \mathrm{MHz}$ bandwidth between $2.34 \mathrm{GHz}$ and $2.46 \mathrm{GHz}$ in the lower frequency band, and $380 \mathrm{MHz}$ bandwidth between $5.2 \mathrm{GHz}$ and $5.52 \mathrm{GHz}$ in the higher frequency band. The antenna is electrically small with the overall size of $0.008 \lambda_{0}$ $\mathrm{x} 0.011 \lambda_{0}$ at $2.4 \mathrm{GHz}$ resonance frequency. The radiation efficiencies are $75 \%$ and $80 \%$ at $2.4 \mathrm{GHz}$ and $5.2 \mathrm{GHz}$, respectively with an omnidirectional radiation pattern. The antenna is mounted along the narrow spacing along the front of the metal housing to provide two wide bands for the 2.4 and 5.2/5.8 GHz WLAN operation in both the open and closed states. Operating principle of the antenna comprising a monopole strip and a loop strip configured to achieve a compact structure has been discussed. Good radiation characteristics for the antenna have also been obtained. Obtained results indicate that the proposed antenna is promising for practical applications. Simulated results showed that the isolation between antennas can be better than $-21 \mathrm{~dB}, 32$, and $34 \mathrm{~dB}$ in the $2.4,5.2$, and $5.8 \mathrm{GHz}$ bands, respectively. The proposed WLAN MIMO antenna array has attractive properties of small size and planar structure, making it promising for applications in STB structures. The proposed antenna can be used in the receiving modules of compact wireless devices operating in MIMO systems.

\section{Acknowledgements} Turkey).

This work has been supported by the Project 114E078 of TUBITAK (scientific and technological research council of

\section{References}

[1] T. Svantesson and A. Ranheim, "mutual coupling effects on the capacityof muti element antenna systems," in Proceedings of IEEE international conference on acoustics, speech, and signal processing (ICASSP), vol. 4, May 2001, pp. 2485-2488.

[2] T.-Y. Wu, S.-T. Fang, and K.-L. Wong, "A printed diversity dual-band monopole antenna for wlan operation in the 2.4 and 5.2 ghz band," Microwave Opt Technol Lett, vol. 36, 2003. 
[3] G. Chi, B. Li, and D. Qi, "Dual band printed diversity antenna for 2.4/5.2 ghz wlan application," Microwave Opt Technol Lett, vol. 45, 2005.

[4] Y. Gao, C. C. Chiau, X. Chen, and C. G. Parini, "Modified PIFA and its array for MIMO terminals," IEEE Proc Microwave Antennas Propag, vol. 152, 2005.

[5] L. C. Chou and K. L. Wong, "Uni-planar dual-band monopole antenna for 2.4/5 GHz WLAN operation in the laptop computer," IEEE Trans. Antennas Propagat., vol. 55, pp. 3739-3741, 2007.

[6] T. W. Kang and K. L. Wong, "Very-small-size printed monopole with embedded chip inductor for 2.4/5.2/5.8 GHz WLAN laptop computer antenna," Microwave Opt. Technol. Lett., vol. 52, pp. 171-177, 2010.

[7] C. H. Chang and K. L. Wong, "Internal coupled-fed shorted monopole antenna for GSM850/900/1800/1900/UMTS operation in the laptop computer," IEEE Trans. Antennas Propagat., vol. 56, pp. 3600-3604, 2008.

[8] K. L. Wong and S. J. Liao, "Uniplanar coupled-fed printed PIFA for WWAN operation in the laptop computer," Microwave Opt. Technol. Lett., vol. 51, pp. 549-554, 2009.

[9] Y. L. Kuo and K. L. Wong "Printed double-T monopole antenna for 2.4/5.2GHz dual band WLAN operations," IEEE Transaction on Antennas and Propagation, 2003, vol. 5, pp. 2187-2192. 